\title{
СБАЛАНСИРОВАННАЯ СИСТЕМА ПОКАЗАТЕЛЕЙ КАК ИННОВАЦИОННЫЙ ИНСТРУМЕНТ УПРАВЛЕНИЯ ПРЕДПРИНИМАТЕЛЬСКИМИ РИСКАМИ МЕЖДУНАРОДНЫХ ГИДРОЭНЕРГЕТИЧЕСКИХ ПРОЕКТОВ
}

\author{
(c) 2020 Рыкунов Илья Владимирович \\ АО «ТЯЖМАШ», Россия, Сызрань \\ E-mail: ivrykunov@yandex.ru
}

На сегодня сложно найти в мире предпринимательскую структуру, ведущую бизнес без рисков. Применительно к деятельности предприятий гидроэнергетики, кроме классических, общеизвестных бизнес-рисков, действуют риски, связанные с использованием основных источников возобновляемой энергии. Целью данного исследования является поиск инновационных инструментов управления рисками международных проектов в области гидроэнергетики. Одним из инновационных инструментов риск-менеджмента предложена сбалансированная система показателей. Автором разработана типология применяемых в отечественной и зарубежной теории и практике моделей системы сбалансированных показателей с позиции возможности их применения при реализации международных проектов гидроэнергетики. Предложен методический подход к формированию интегрированного процесса применения системы сбалансированных показателей и риск менеджмента для управления рисками международных проектов предприятий гидроэнергетики. Полученные результаты предназначены для разработки комплекса управленческих решений, принимаемых менеджментом гидроэнергетических предприятий при разработке системы риск-менеджмента, что расширяет возможности успешного управления международными гидроэнергетическими проектами.

Ключевые слова: международные проекты, инновации, гидроэнергетика, бизнес, предпринимательство, предприятия машиностроения, риск-менеджмент.

\section{Введение}

Деятельность предприятий гидроэнергетики сопряжена с огромным количеством разнообразных рисков. Процессы управления рисками предприятий гидроэнергетики, реализующих международные проекты, прежде всего, связаны с ограниченной возможностью выявления их действия. В трудах российских ученых подчеркивается важность решения проблемы выявления и эффективного управления рисками.

Так, например, в труде Гуськовой Н.Д. и Ульянкина О.В. затронута проблема необходимости формирования объемной картины рисков энергосервисных компаний (ЭСКО) [1]. Рассмотрены существующие классификации рисков ЭСКО и отмечены их ключевые недостатки, которые подтвердили предположение о наличии пробела в теории в данной области и детерминировали необходимость создания новых классификаций рисков. ГуськовойН.Д. и Ульянкиным О.В. предложены две оригинальные классификации рисков энергосервисных компаний. Первая классификация рисков разработана согласно этапам реализации перформанс- контракта. Вторая классификация рисков ЭСКО сформирована по признаку источника возникновения риска. Дополнительно был выделен риск работы с нежелательными клиентами, который не вошел ни в одну из представленных классификаций.

Ю.Н. Макаревич и И.А. Соболь в своей статье «...рассматривают важную проблему снижения влияния рисков, возникающих в энергетической отрасли» [2].

В работе А.Ю.Домникова и др., подчеркивается, что «...Особую значимость ...приобретает совершенствование систем управления отраслевыми рисками, необходимое для достижения долгосрочного роста и устойчивого развития энергетического сектора в условиях множественности и неопределенности факторов, создаваемых глобализацией финансовых рынков. Ими предложен подход к оценке отраслевых рисков энергетической сферы» [3].

Н.М. Боброва подчеркивает, что «...Планирование управления рисками является ключевым элементом системы управления рисками» [4].

М.А.Найдановой и А. О. Алексеевым при ис- 
следовании компетенций в области анализа и управления рисками, требующихся специалистам по управлению рисками, «... выполнен сравнительный анализ трудовых функций риск-менеджеров из профессионального стандарта и предлагаемых дополнительных функций, который позволил разработать процессную модель анализа и управления рисками, согласующуюся с принципом Шухарта-Деминга (PDCA)» [5].

Кевин Найт, который признан самым авторитетным специалистом в мире в области создания, объяснения и продвижения стандартов управления риском в своем интервью журналу «Проблемы анализа риска» в 2011 году сказал «... Когда я контролирую ситуацию, мне хорошо» [6].

В статьях [7,8] авторами сформулированы риски предпринимательской деятельности при реализации международных гидроэнергетических проектов и инструмент эффективного управления ими.

Но выявление рисков является только началом решения проблемы управления ими. Целью данного исследования является поиск инновационных инструментов системы риск-менеджмента предприятий гидроэнергетики, реализующих международные проекты. Считаем, что одним из действенных инструментов управления рисками является сбалансированная система показателей.

В настоящей статье сделан акцент не на классификации рисков, а на формулировании инструментов управления ими на основе применения концепции сбалансированной системы показателей деятельности гидроэнергетического предприятия, реализующего международные проекты в области производства гидротурбинного оборудования. При этом исследуются некоторые аспекты формирования данной системы как инструмента по оценке рисков предпринимательских структур и бизнеса, работающего в области гидроэнергетики.

Использование сбалансированной системы показателей позволяет определить основные направления стратегического развития предприятия, заблаговременно принять меры, предотвращающие нежелательное развитие событий, и выявить скрытые возможности развития предприятия. Сознательное, рациональное отношение к риску расширяет возможности успешного управления международными гидроэнергетическими проектами.

\section{Данные и методы}

Методологической и теоретической основой исследования являются:

- метод комплексного анализа, который дал возможность охватить широкий ряд проблем, связанных с управлением рисками международных проектов в предпринимательских структурах гидроэнергетики, а также систем сбалансированных показателей, применяемых в отечественной и зарубежной теории и практике;

- метод системного анализа, с помощью которого исследованы характер и сущность применяемых моделей сбалансированных систем показателей и сформулирована концепция их применения как инновационного инструмента системы риск-менеджмента;

- концепция рационального поведения рыночных субъектов, принципы которой позволили выявить и сформулировать преимущества и недостатки применения различных сбалансированных систем показателей и разработать их типологическую матрицу;

- метод монографического кабинетного исследования, позволивший выявить вклад российских и зарубежных ученых в развитие теории и практики управления рисками международных проектов в области гидроэнергетики.

Экспериментальная база исследования - совместные производственные российско-зарубежные предприятия, реализующие проекты производства под ключ гидроэнергетического оборудования.

\section{Полученные результаты}

1. Теоретическое обоснование применения сбалансированной системы показателей как инновационного инструмента мониторинга и снижения риска деятельности предприятий.

Разносторонним и единым процессом, в условиях формирования рыночных отношений является управление рисками при производстве уникального оборудования. Трудность его применения на практике зачастую приводит к тому, что на конкретной стадии работы руководство ограничивается применением только тех управленческих рычагов, которые кажутся им нужными и более результативными. Любая организация, осуществляющая международное сотрудничество - это уникальная система, которая проходит последовательные этапы своего жизненного цикла, имеет общие, специальные и 
уникальные параметры деятельности, самостоятельно формулирует цели деятельности в конкретных сегментах глобального рынка, порядок и средства их осуществления, а также связанные с ней риски.

Концепция сбалансированной системы показателей рассматривает финансовые показатели организации как составляющие четырех важных элементов, с акцентами на: рыночные условия, отношения с покупателями, операционную производительность и человеческий потенциал организации. Важным в данной системе является не значение конкретных (единичных) показателей, а их сбалансированность и связь. Данное условие дает возможность осуществлять оперативный мониторинг формирования эффективности деятельности и производительности организации и четко устанавливать вероятные отклонения. Подобным обязан быть и инструмент для контролирования и наблюдения заданной тенденции в выполнении корпоративной стратегии. Одной из целей принципа сбалансированности является исключение возможности манипулирования одной группой показателей за счет других.

В непростых обстоятельствах нынешней рыночной экономики любое управленческое решение, в особенности стратегическое, затрагивающее предстоящее развитие организации постоянно сопряжено с влиянием факторов неопределенности, а, значит, с рисками. Особенно ярко эти риски проявляются в международных проектах гидроэнергетики, так как данная отрасль полностью зависит от факторов явлений природы, социума, политики, экономики, поскольку проекты направлены на использование энергии возобновляемых источников [7].

Считаем, что система сбалансированных показателей является не только индикатором эффективности деятельности предприятия, но и одновременно инструментом управления рисками. Это обстоятельство объясняется следующим. В рамках сбалансированной системы показателей происходит формирование взаимосвязанных и взаимозависимых показателей, отражающих желаемую критериальную оценку производственных и управленческих событий при реализации международных проектов. В свою очередь, те же сбалансированные показатели могут быть сформированы так, что они связаны с событиями концепции риск-менеджмента предприятия. В этом случае мониторинг состояния сбалансированных показателей при их отклонении от заданных величин, позволяет выявить и оценить не только возможные риски, но направления снижения их влияния. Исследования авторов в области реализации международных проектов в области гидроэнергетики, позволяют утверждать, что это сложная задача, т.к. в большинстве проектов при создании интегрированной модели сбалансированной системы показателей и риск-менеджмента требуется по нескольку месяцев на каждую ступень построения её организационной иерархии [8]. Выстроенная интегрированная модель дает возможность осуществлять административные решения стратегического и оперативного характера, в т.ч. и связанные с управлением рисками.

2. Типология и методические аспекты обоснования применения сбалансированной системы показателей как инновационного инструмента управления рисками.

Основным инструментом стратегического управления является концепция сбалансированной системы показателей.

Формирование концепции сбалансированной системы показателей начали еще в 1990-х годах американские ученые Роберт Каплан и Дэйвид Нортон, Лоренц Мейсель и другие, после чего она обрела дальнейшее развитие, была успешно испытана на практике в странах с развитой рыночной экономикой, а в завершении, приобрела интернациональное признание.

Модель Нортона-Каплана в настоящее время признана одной из известных эффективных концепций [9]. Основной акцент модели нацелен на причинно-следственную взаимосвязь среди отдельных ключевых показателей и элементов деятельности организации. Непосредственно внутренняя логика, связь единичных характеристик по подразделениям и областям деятельности предприятия и признаются предметом «балансирования» показателей. В сбалансированной системе показателей предлагается поэтапное создание основных контрольных показателей, включающих в себя четыре базовых области приложения усилий, либо использования возможностей - капитал, покупатели, внутренние бизнес-процессы, обучение и развитие. Главная цель концепции сбалансированной системы показателей - балансировка деятельности организации во времени и пространстве. Критериальные показатели системы, используемые с целью контроля, обязаны соответство- 
вать тактическим задачам, разрабатываются на базе стратегических целей и должны сохранить устойчивое развитие организацию в заданном направлении.

Существенным преимуществом концепции является то, что любая запланированная стратегия в рамках установленной миссии, формализованная и детализированная в стратегических картах, дает возможность топ-менеджерам предоставить доступную информацию любому сотруднику на всех ступенях иерархии в предпринимательской структуре, будь то мелкая компания либо крупное машиностроительное предприятие.

Лоренц Мейсель в своей сбалансированной системе показателей акцентирует внимание на четырех базовых нюансах, по которым определяется бизнес организации. В рамках данного аспекта анализу подвергается инновационная деятельность, обучение персонала, усовершенствование продукции, формирование корпоративной культуры и ответственности фирмы.

Целью концепции модели Кристофера Адамса и Питера Робертса является обеспечение введения стратегии фирмы в формирование культуры, в которой совершаются стабильные перемены. Показатели производительности обязаны обеспечить работников, которые принимают решения и отвечают за осуществление стратегии, стремительной обратной связью [10].

Одной из «ранних» моделей, разработанной Питером Друкером является концепция «управления по миссиям». Суть данной модели выражается в управлении как единой системы, нацеленной на выполнение миссий и задач, которые стоят перед компанией. Одной из идей является то, что все менеджеры фирмы обязаны быть причастны к реализации стратегического планирования, а, кроме того, к разработке инициатив, нацеленных на увеличение производительности и результатов функционирования компании.

Модель, разработанная Карлом-Эриком Свейби, создает интегральный показатель, применяемый в управлении компетенциями, которые рассматриваются как база развития знаний и ценности организации. Она основывается на способе измерения нематериальных активов.

Сформированная Лейфом Эдвинссоном модель нацелена на преимущество значимости управления и мотивации, она подразумевает под собой концепцию оценки нематериальных активов с позиции единства восприятия работы фирмы по достижению целей. В рассматриваемой модели акцентируют внимание на пяти областях, в которых сосредоточиваются разнообразные сферы интересов и визуализируется процедура развития ценности в фирме: капитал, направленность на покупателя, процессы, восстановление работы и формирование организации, человеческий фактор [11].

Автором разработана типология применяемых в отечественной и зарубежной теории и практике моделей сбалансированной системы показателей с позиции возможностей ее применения при реализации международных гидроэнергетических проектов (см. табл.1).

В настоящей статье основной интерес направлен на взаимосвязь сбалансированной системы показателей и концепции управления рисками международных проектов в сфере гидроэнергетики, миссия которой заключается в увеличении внутриорганизационной прозрачности, формирования риск-ориентированного мышления и ответственности у работников.

Планирование, анализ и наблюдение рисков, а также управление ими являются базовыми стадиями построения интегрированной концепции своевременного управления рисками. Одновременно с данными стадиями проходит процедура документирования.

На стадии оценки каждая координационная часть определяет группы своих рисков и возможные угрозы в каждой из них, важные с точки зрения управления международными проектами. В концепции управления рисками немаловажно производить оценку предпосылок формирования стратегии компании.

Если рассматривать сущность процессов формирования сбалансированной системы показателей и внедрения риск-менеджмента, то их связывают две особенности. Во-первых, концепция управления рисками, как и сбалансированная система показателей, базируется на применении проактивных индикаторов. Во-вторых, в обеих концепциях прописываются события, необходимые для свершения целей и снижения рисков.

Как демонстрирует зарубежный опыт, включение управления рисками в единую концепцию управления предприятием наиболее производительно, если оно непосредственно сопряжено со стратегическими миссиями фирмы.

При создании подобных сценариев прини- 
Таблица 1. Типология применения моделей сбалансированной системы показателей при реализации международных проектов гидроэнергетики

\begin{tabular}{|c|c|c|}
\hline \multirow{2}{*}{$\begin{array}{c}\text { Автор и структура модели сбалансиро- } \\
\text { ванной системы показателей }\end{array}$} & \multicolumn{2}{|c|}{$\begin{array}{c}\text { Возможность применения при реализации международных } \\
\text { проектов гидроэнергетики }\end{array}$} \\
\hline & Достоинства & Недостатки \\
\hline $\begin{array}{l}\text { Питер Друкер } \\
\text { Структура: } \\
\text { - миссия и задачи, } \\
\text { - стратегическое планирование, } \\
\text { - производительность }\end{array}$ & $\begin{array}{l}\text { Управление как единая система, } \\
\text { полагающаяся на выполнение } \\
\text { миссий и задач }\end{array}$ & $\begin{array}{l}\text { Не все менеджеры способны } \\
\text { выходить с инициативами, } \\
\text { нацеленными на увеличение } \\
\text { производительности компании }\end{array}$ \\
\hline $\begin{array}{l}\text { Дейвид П. Нортон, Роберт С. Каплан. } \\
\text { Структура: } \\
\text { - капитал, } \\
\text { - покупатели, } \\
\text { - внутренние бизнес-процессы, } \\
\text { - обучение и развитие }\end{array}$ & $\begin{array}{l}\text { Раскрывает причинно- } \\
\text { следственные связи среди от- } \\
\text { дельных показателей и элемен- } \\
\text { тов деятельности }\end{array}$ & $\begin{array}{l}\text { Сложность обоснования показа- } \\
\text { телей и их взаимосвязей }\end{array}$ \\
\hline $\begin{array}{l}\text { Лоренц, Мейсель } \\
\text { Структура: } \\
\text { - инновационная деятельность, } \\
\text { - обучение персонала, } \\
\text { - усовершенствование продукции, } \\
\text { - формирование корпоративной куль- } \\
\text { туры и ответственности фирмы }\end{array}$ & $\begin{array}{l}\text { Акцент на инноватике во } \\
\text { многих областях деятельности } \\
\text { предприятия }\end{array}$ & $\begin{array}{l}\text { Не учитывается стратегическое } \\
\text { планирование развитием пред- } \\
\text { приятия }\end{array}$ \\
\hline $\begin{array}{l}\text { К. Адамс и П. Робертс } \\
\text { Структура: } \\
\text { - стратегия фирмы, } \\
\text { - мотивация, } \\
\text { - формирование орг.культуры }\end{array}$ & $\begin{array}{l}\text { Мотивация работников, кото- } \\
\text { рые принимают решения, за } \\
\text { счет показателей стратегии } \\
\text { предприятия }\end{array}$ & $\begin{array}{l}\text { Сложность введения стратегии } \\
\text { предприятия в формирование } \\
\text { культуры, в которой совершают- } \\
\text { ся стабильные перемены }\end{array}$ \\
\hline $\begin{array}{l}\text { K. Свейби } \\
\text { Структура: } \\
\text { - управление компетенциями, } \\
\text { - знания, } \\
\text { - нематериальные активы }\end{array}$ & $\begin{array}{l}\text { Применение интегрального } \\
\text { показателя в управлении ком- } \\
\text { петенциями, которые рассма- } \\
\text { триваются как база развития } \\
\text { знаний иценности организации }\end{array}$ & $\begin{array}{l}\text { Основывается на способе изме- } \\
\text { рения нематериальных активов }\end{array}$ \\
\hline $\begin{array}{l}\text { Л. Эдвинссон } \\
\text { Структура: } \\
\text { - капитал, } \\
\text { - направленность на покупателя, } \\
\text { - процессы, } \\
\text { - восстановление работы и формиро- } \\
\text { вание организации, } \\
\text { - человеческий фактор }\end{array}$ & $\begin{array}{l}\text { Модель нацелена на преимуще- } \\
\text { ство значимости управления и } \\
\text { мотивации }\end{array}$ & $\begin{array}{l}\text { Подразумевает под собой кон- } \\
\text { цепцию оценки нематериаль- } \\
\text { ных активов с позиции единства } \\
\text { восприятия работы предприя- } \\
\text { тия по достижению целей }\end{array}$ \\
\hline
\end{tabular}

мается во внимание воздействие всех идентифицированных рисков на стратегические миссии. Данное обстоятельство помогает определять реальные целевые значения стратегических характеристик. Помимо этого, целесообразно объединение риск-менеджмента с концепцией мотивации персонала, своевременного и стратегического планирования.

На основе результатов анализа автором сделаны следующие выводы, лежащие в основе модели автора:

- требуется постоянная мотивация менеджера, способного проявить инициативу в прогнозировании и выявлении рисков в реализации проекта; затраты на данную мотивацию будут несоизмеримо более низкими, чем стоимость устранения последствий наступления рисков (например, срыв сроков поставки гидротурбины от срыва сроков поставки литья или поковок);

- показатели внутренних бизнес-процессов предприятия должны быть простыми, понятными и прозрачными;

- цели и задачи менеджерам должны коррелироваться с основными стратегическими бизнес-целями предприятия.

На основе проведенного исследования взаимосвязи сбалансированной системы показателей и концепции управления рисками автором сформирован следующий интегрированный процесс применения системы сбалансированных показателей для управления рисками международных проектов предприятий гидроэнергетики, изображенный в виде таблицы 2.

Таким образом, специфика управления ги- 
Таблица 2. Функции управления рисками на этапах разработки и реализации ССП гидроэнергетического проекта

\begin{tabular}{|c|c|}
\hline $\begin{array}{c}\text { Этапы реализации системы сбалансированных } \\
\text { показателей }\end{array}$ & Функции системы управления рисками \\
\hline \multicolumn{2}{|c|}{ Стадия формирования ССП } \\
\hline $\begin{array}{l}\text { 1. Исследование стратегии деятельности компании } \\
\text { в глобальной среде, распознавание стратегических } \\
\text { миссий }\end{array}$ & $\begin{array}{l}\text { Выявление наиболее вероятных рисков, сопряжен- } \\
\text { ных с реализацией проекта }\end{array}$ \\
\hline $\begin{array}{l}\text { 2. Оценка специфики проектной деятельности пред- } \\
\text { приятий гидроэнергетической отрасли на стадиях: } \\
\text { - предпроектной; } \\
\text { - проектной; } \\
\text { - послепроектной (строительство и функциониро- } \\
\text { вание объекта) }\end{array}$ & $\begin{array}{l}\text { Выявление ключевых рисков, оказывающих суще- } \\
\text { ственное влияние на реализацию проекта на стади- } \\
\text { ях: } \\
\text { - предпроектной; } \\
\text { - проектной; } \\
\text { - послепроектной (строительство и функциониро- } \\
\text { вание объекта) }\end{array}$ \\
\hline $\begin{array}{l}\text { 3. Выявление и обоснование критериальных показа- } \\
\text { телей деятельности предприятия гидроэнергетики } \\
\text { на стадиях: } \\
\text { - предпроектной; } \\
\text { - проектной; } \\
\text { - послепроектной (строительство и функциониро- } \\
\text { вание объекта) }\end{array}$ & $\begin{array}{l}\text { Создание причинно-следственной цепочки количе- } \\
\text { ственного определения рисков, отклонение которых } \\
\text { позволит произвести оценки рисковых ситуаций }\end{array}$ \\
\hline $\begin{array}{l}\text { 4. Разработка методики расчета показателей, вклю- } \\
\text { ченных в ССП }\end{array}$ & $\begin{array}{l}\text { Разработка методики оценки рисков невыполнения } \\
\text { показателей ССП }\end{array}$ \\
\hline \multicolumn{2}{|c|}{ Стадия реализации ССП } \\
\hline $\begin{array}{l}\text { 1. Оценка степени выполнения показателей ССП } \\
\text { проекта }\end{array}$ & Оценка сопряженных рисков проекта \\
\hline $\begin{array}{l}\text { 2. Выявление отклонений от заданных уровней ССП } \\
\text { по каждому этапу реализации проекта }\end{array}$ & $\begin{array}{l}\text { Разработка мероприятий (проектов) управления } \\
\text { рисками по каждому отклонению }\end{array}$ \\
\hline $\begin{array}{l}\text { 3. Формирование банка данных по оперативному } \\
\text { контролю показателей реализации проекта }\end{array}$ & $\begin{array}{l}\text { Формирование банка мероприятий управления вы- } \\
\text { явленными рисками }\end{array}$ \\
\hline
\end{tabular}

дроэнергетическим проектом заключается в каждом этапе его реализации:

- исследование стратегии деятельности компании в глобальной среде для определения ее потенциала для участия в мировых тендерах по строительству и модернизациям гидроэлектростанций;

- распознавание стратегических миссий и рисков;

- формирование сбалансированной системы показателей и выделение в ней критериальных показателей деятельности предприятия, отклонение от которых позволит произвести оценки рисковых ситуаций реализации проекта;

- создание причинно-следственной цепочки количественного определения рисков, с учетом специфики предприятий гидроэнергетической отрасли;

- составление плана рисков и постановка целей управления ими;

- разработка мероприятий по управлению рисками в области гидроэнергетики;

- составление отчетности (формирование банка мероприятий управления выявленными рисками);

- оценка и выявления новых рисков, существенно влияющих на деятельности предприятий гидроэнергетики.

\section{Заключение}

Подводя итоги данного исследования, можно сделать следующие выводы:

- концепция управления рисками, как и сбалансированной системы показателей, базируется на применении проактивных показателей, что особенно актуально для предприятий гидроэнергетики. В рассмотренных моделях прописываются события, необходимые для свершения задач организации и снижения рисков;

- единая концепция управления гидроэнергетическим предприятием, включающая подсистему управления рисками, наиболее производительна в том случае, если она непосредственно сопряжена со стратегическими целями его развития;

- управление рисками международных гидроэнергетических проектов возможно осуществлять с помощью системы сбалансирован- 
ных показателей, мониторинг отклонений от критериальных значений которых позволяет предвидеть рисковые события и управлять ими.

Предлагаемые результаты исследования могут быть полезны предпринимателям при разработке методов риск-менеджмента, а также комплекса управленческих решений по выявлению рисковых ситуаций и управлению ими. Методически эту технологию раскрывает разработанный и внедренный автором подход к управлению рисками на основе системы сбалансированных показателей, представленный в разработанном интегрированном процессе применения системы сбалансированных показателей для управления рисками международных проектов предприятий гидроэнергетики.

\section{Библиографический список}

1. Гуськова Н.Д., Ульянкин О.В. Формирование объемной картины рисков энергосервисных компаний //Проблемы анализа риска. 2015. Т. 12. № 3. С. 10-22.

2. Макаревич Ю.Н., СобольИ.А. Управление рисками, возникающими в процессе функционирования энергетических систем, как фактор управления их экономической безопасностью. Вестник Санкт-Петербургского университета МВД России. 2008. № 1 (37). С. 127-131.

3. Домников А.Ю. ЧеботареваГ.С., Хоменко П.М. Риск-ориентированный подход к управлению капиталом энергетической компании. Вестник УрФУ. Серия: Экономика и управление. 2014. № 6. С. 150-160.

4. Боброва Н.М. Планирование управления рисками как ключевой элемент системы управления рисками. Экономика и предпринимательство. 2014. № 11-3 (52). С. 808-811.

5. Найданова М.А., Алексеев А. О. Компетенции в области анализа и управления рисками, требующиеся специалистам по управлению рисками Master’sJournal. 2016. № 2. C. 402-410.

6. Сорогин А.А. «Когда я контролирую ситуацию, мне хорошо». Эксклюзивное интервью с Кевином Найтом// Проблемы анализа риска. 2011. Т. 8. № 1. С. 6-11.

7. Рыкунов И.В. Риски предпринимательской деятельности при реализации международных гидроэнергетических проектов // Экономика и предпринимательство.-2017. - № 12 (ч.1) (89-1) 2017 г., С. 466-469.

8. Волкодавова Е.В., Рыкунов И.В. Проектный и постпроектный инжиниринг как инструменты эффективного управления международным проектом «под ключ» при возведении ГЭС // Экономика и предпринимательство. - 2015. - № 8 (ч.2).- С. 149-152.

9. Каплан Роберт С., Нортон Дейвид П. Сбалансированная система показателей. Отстратегиикдействию. М.: Олимп-Бизнес, 2006. 304 с.

10. Крылов С.И. Сбалансированная система показателей как аналитический инструмент стратегического управления в условиях современной рыночной экономики // Экономический анализ: теория и практика. 2007. № 24. C. 2-10.

11. Фридаг Хервиг Р., Шмидт Вальтер. Сбалансированная система показателей: руководство по внедрению. М.: Омега-Л, 2006. 272 с. 